Plant Molecular Biology 11: 539 (1988)

(C) Kluwer Academic Publishers, Dordrecht - Printed in the Netherlands

Erratum

\title{
Isolation and sequence of a tomato cDNA clone encoding subunit II of the photosystem I reaction center
}

Neil E. Hoffman, Eran Pichersky, Vedpal S. Malik, Kenton Ko and Anthony R. Cashmore

Plant Molecular Biology, Volume 10, No. 5, pp. 435-445 (1988)

One page 441 of the above article some matter is missing from the right-hand column. The full text from lines 16-25 should read as follows:

oids. Truncated CAB3 is not detected in Fig. 6, lanes 6,7 , or 9 because the antibody employed, MLH1, recognizes an epitope on the $\mathrm{N}$-terminal side of the protease sensitive site [8]. OEC-33, located on the lumen side of the membrane, was degraded by protease only after sonication (Fig. 6, lane 6 versus 9). Collectively these data imply that subunit II is proteaseinsensitive in its assembled conformation and hence it is unlikely that selective proteolysis will reveal the membrane localization. 